\title{
Applying a Reading Program Based on Cognitive Science in Rural Areas of Malawi: Preliminary Results
}

\author{
Radhika Iyengar $^{1}$, Alia Karim ${ }^{2}$, Florie Chagwira ${ }^{3}$ \\ ${ }^{1}$ Radhika Iyengar, Associate Research Scholar, Earth Institute, Columbia University, USA \\ ${ }^{2}$ Senior Education Specialist, Center on Sustainable Development, Earth Institute, Columbia University, USA \\ ${ }^{3}$ Education Sector lead, Millennium Promise, Mwandama, Millennium Villages Project, USA \\ Correspondence: Radhika Iyengar, 475 Riverside Drive, Suite 239, Interchurch Center, New York, New York -10115, \\ USA . Phone-212-870-2785
}

Received: February 23, 2016

Accepted: March 22, 2016 Online Published: March 30, 2016

doi:10.11114/jets.v4i5.1504

URL: http://dx.doi.org/10.11114/jets.v4i5.1504

\begin{abstract}
Reading fluency is a skill foundational to academic performance, and acquiring this skill in early grades is crucial. Throughout sub-Saharan Africa, reading levels of students are far below grade level, and Malawi is no exception. Research suggests that students, particularly in consistently spelled languages, acquire automaticity most easily by starting from individual letters, combining them in increasingly larger chunks, and getting plenty of practice in decoding them. Due to working memory capacity limits, students must attain a minimum reading speed in order to understand text. These concepts were tested in a rural district in Malawi. The study helps to explain the components of this science-based "learning package" needed for reading fluency. Volunteers held the classes in communities as an after school program for children from grades 1 to 5 . The goal behind this innovative six-month program is students' recognition of all letters used in Chichewa language and progress in text decoding. This study helps to explain the various components of the learning intervention and the results show that there has been improvement in knowledge of letter sounds. This study uses an already tried and tested cognitive neuroscience model, which was contextualized and implemented in the Malawi setting.
\end{abstract}

Keywords: cognitive-neuroscience, early grade reading, local language, early grade literacy, Malawi

\section{Introduction}

\subsection{The Learning Crises}

Since 1990, when the Education for All initiative started, there has been much progress in improving enrollment rates. However, a hidden education crisis has been brewing in many developing countries; children attend school regularly but they may learn very little (Center for Universal Education at Brookings, 2011). To combat this crisis, the UN Secretary General announced the Education First campaign in $2012^{1}$. The main priorities include putting everyone in school, improving the quality of learning and fostering global citizenship. While these priorities are a step in the right direction, many education specialists have been unsure how to train the poorest and most marginalized students, who face particular disadvantages, such as learning from teachers with limited education.

This learning crisis especially affects the poor populations of most low-income countries (Beatty \& Pritchett, 2012). For example, studies from Kenya 11 out of 100 children in class ${ }^{2}$ cannot do simple division while in second grade (UWEZO Kenya, 2012). Furthermore, 7 out of 100 can neither read a simple English nor a Kiswahili story. UWEZO tests results from Kenya show that on average only 3 out of 10 children in grade 3 can do grade 2 level work. UWEZO Uganda (2011) has a similar story to tell. In Uganda at least 9 out of every $10(92 \%)$ of all children in $\mathrm{P}^{3}$ could not read a P2 English level story text; and of all children in P3 who could read a P2 English level story text, at least one out

\footnotetext{
${ }^{1}$ For more details, please visit: http://www.globaleducationfirst.org/about.html

${ }^{2}$ In Kenya, grades and standards are called class.

${ }^{3}$ In Uganda, P3 or Primary 3 is equivalent to Grade 3 or Standard 3 in other countries.
} 
of ten failed comprehend the story. Results from UWEZO Tanzania (2011) similarly showed that only 3 out of 10 Standard 3 pupils could read a basic story in Kiswahili and only 1 out of 10 Standard 3 pupils could read a basic story in English. The results were no better in mathematics; only 3 out of 10 students could add, subtract and multiply.

Malawi is no exception to poor education quality. An Early Grade Reading Assessment (EGRA) in 2010 showed that $72.8 \%$ of second graders and $41.9 \%$ of fourth graders were unable to read a story in Chichewa, the national language. ${ }^{5}$ The learning outcomes of the poor might improve if teaching methods were developed on the basis of memory functions. Research suggests that students, particularly in consistently spelled languages (the way you write is the way you speak), acquire automaticity most easily by starting from individual letters, combining them in increasingly larger chunks, and getting plenty of practice in decoding them (Abadzi, 2013). Feedback is an essential part of the process. Due to working memory capacity limits, students must attain a minimum reading speed in order to understand text. This means that for the students to understand what they read, they must read it fast enough. Slow readers forget what they read by the end of the sentence. The students must become competent in quickly identifying individual letters and sounds, then composing them. Unlike English, mere knowledge of letter sounds and practice in composing them reliably evokes Chichewa words (Seymour et. al., 2003). In addition, letter spacing and fonts must be optimized, as suggested by USAID-sponsored research (DeJongh, 2014). A method of combining these elements should teach fluent and effortless reading to nearly all children.

Programs combining many or most of these information-processing features have been tested in some countries, such as the Gambia and Egypt (Zafeirakou, 2014; Abadzi, 2013) and have shown very good results. In the Gambia, for example, only after half of the planned lesson in the course taught on average, 69\% of first graders in the Pulaar language and 57\% of first graders in Wolof language knew at least $80 \%$ of the letters (target was $85 \%$ of children) (Abadzi, 2013). Similar progress was noted in Egypt after six months of application in grade 2. Word and text reading fluency rates doubled in comparison to rates obtained two years earlier (from 7 to 15 and from 11 to 21 words per minute respectively; syllable reading tripled from 10 to 28 syllables per minute. By contrast, the same measures in comparison schools improved only by about $27 \%$. The percentage of students reading 0 correct words was cut by half in project schools (from $44 \%$ to $21 \%$ ) while in comparison schools it improved only by $10 \%$ (USAID, 2012). The Egyptian program has been scaled up nationwide, while the Gambian pilot has also expanded.

This study used the lessons from the Gambia and Egypt to simplify and streamline the instructional routines, aiming at the variables that most efficiently create automaticity: phonics, decoding, brief individual feedback, and practice. The goal was attainment of reading speed necessary to comprehend about $80 \%$ of the text. Details are mentioned in this and other sections. The study uses the principles of cognitive neuroscience on how children learn and contextualizes them to the Malawian settings. This applied research helps to understand the process of using learning principles translated into textbook development, developing simple routines for teacher training and classroom-based practices. The study discusses the importance of each element of the program and the relevance of cognitive neuroscience in understanding how children in low-resources settings could improve their learning rates. The specific research objectives of the study include the following: To increase students' reading performance in selected rural areas of Malawi through the use of consistently spelled local languages. The second objective is to measure and monitor how students acquire reading as a function of inputs, methodology, and instructional time.

\subsection{The Organizational Structure}

The Millennium Village Project (MVP) started an education program in Mwandama, Malawi in 2005. Mwandama is located in the Zomba district in the Southern Region of Malawi. It consists of 114 villages, including 14 primary schools and 2 community day schools. In this area, the Millennium Villages Project is carrying out a rural integrated development program to complement government efforts. Educational activities include capacity building of community structures and teachers, infrastructure development, provision of teaching and learning materials, school feeding, scholarship program and school health.

As a push towards early grade literacy, in 2014 MVP Mwandama organized 27 active Village Learning Centers (VLCs), across all of 7 of its village clusters. ${ }^{6}$ These VLCs are run by hired Community Education Workers (CEWS) who typically have completed secondary school, and are local residents of the villages they serve. Their responsibilities include community mobilization for school enrollment, household visits to follow up on student absenteeism and

\footnotetext{
${ }^{4}$ In Tanzania, Standard 3 is $w=$ equivalent to Grade 3 in other countries.

${ }^{5}$ Retrieved from https://www.eddataglobal.org/

${ }^{6}$ Mwandama Cluster MVP sections include: Dindi, Katete, Makoka, Msamba, Mwandama, Nambande, and Nswanswa.
} 
dropouts, and teaching supplemental classes after school at the VLCs. The CEW program currently reaches 1,125 children through their community-based VLC classes. Children of all ages are encouraged to attend, and do not have to be enrolled in school to do so, although the majority of children attending are in school. VLCs are held in a variety of spaces within the community, from school classrooms to churches to community spaces and temporary structures.

\subsection{Theoretical Framework}

The language policy in Malawi has undergone many changes. In 1996, the government declared that standards (grade levels) 1-4 in primary school would be taught in their mother tongue, with English and Chichewa offered as subjects (Moyo, 2001). The mother tongue language of instruction for a particular school was determined as the "language commonly spoken in the area where the school is located" (Ministry of Education, 1996 as cited in Chilora, 2000). From standard 5 onwards, English would be the language of instruction with the national language of Chichewa and other languages, such as French, offered as a subject (US Embassy Malawi). However, the implementation of this policy has proven to be challenging, as teachers are not always familiar with the language of the community and adequate materials are not available (Kayambazinthu, 1998 as cited in Moyo, 2001). However, a 2013 Education Act $^{7}$ decreed that all primary school classes should be conducted in English. This directive has similarly created controversies because many teachers lack good command of English. And, unlike Chichewa and most other languages of the world, English has unusual spelling complexities.

Given this backdrop, the MVP Education Sector decided to develop an intervention targeted at improving local language literacy, focused on Chichewa, which is the language taught nationally in schools even though a variety of other local languages exist within Malawi. Cognitive science-based principles on learning transparent orthographies, as spelled out in (Abadzi, 2012; 2013) were applied to Chichewa in this project. As per this literature, since Chichewa is spelled consistently (they way you write it is the way you speak), and letter sounds and basic decoding skills could be gained within just a few months. The objectives of MVP's local language literacy program were to: (a) to increase students' reading performance in some rural areas of Malawi (b) to measure and monitor how students acquire reading as a function of inputs, methodology, and instructional time.

Methods imported from high-income countries often include enrichment activities and multiple types of materials. Used by educated and competent teachers, these may be very helpful, but teachers with limited education may suffer from working memory overload (Feldon, 2007), which interrupts the information processing. This implies that information is not processed because of a lot of instruction being passed on in a limited time. For this reason, the number of activities or steps that teachers needed to follow was minimized to those that maximize practice with known and detectible shapes.

Cognitive science research and experiences from the Gambia and other countries show that a great deal of attention must be placed in the earliest stages of reading. Children in Malawi often go to grade 1 without having had much prior exposure to print and books. They must first and foremost understand what letter symbols do. Many students may also have difficulty in identifying the same shape in different sizes and in focusing on a target letter among others (Franceschini, Gori, Ruffino, Pedrolli \& Facoetti, 2012; Marinelli, Martelli, \& Zocolotti, 2012). Data on these variables from low-income countries do not exist, so the study tried empirically to ascertain which letter sizes and shapes beginning students could view easily.

This reading method explicitly teaches students one letter at a time, in the same font but in different sizes in the hopes of allowing students to differentiate between symbols, and creating perceptual size constancy. Instruction starts with the most frequent letters (as has been traditionally done by Summer Institute of Linguistics), rather than following the traditional alphabetic order. One new letter is introduced every one or two days; focusing on the sound the letter makes, and slowly incorporating other letters to form chunks of two, three, and four letters. In response to research suggesting that people automatize the simplest shapes most easily, the lower- and upper-case letters are taught separately.

The teacher must direct all students to pay attention to a large letter on the board or a flashcard, show the shape and give

${ }^{7}$ The 2013 Education Act is the result of an eight-year Malawi Law Commission review (2002-2010) to re-draft outdated education legislation in place since 1962. The reformed education bill, announced in March 2014, reinforces primary education for all, promotes the recruitment of new teachers and the building of additional classrooms, and affords the Minister of Education the power to choose the language of instruction for Malawi schools as he or she sees fit.

http://www.aljazeera.com/news/africa/2014/08/malawi-schools-teach-english-local-debate-colonial-2014821840411562 72.html

http://allafrica.com/stories/201311010769.html 
only the letter sound (rather than the letter name). To maintain attention to the shape, few words are used during the presentation. Children could point to the letter towards the blackboard or touch the correct letter on their books. This may facilitate a neural process called long-term potentiation, which inculcates items permanently in memory with few tries (e.g. Arai et. al., 2009). For that, textbooks have letters presented large enough for children to touch with their fingers and still be able to see.

Teachers present the letter sounds, show students how to decode different letter combinations and words, and then spend about half the time supervising students' individual reading. They were asked to pass by every student and offer feedback for at least a few seconds. This was in response to observations in various parts of the world that teachers may work with the few who can perform and neglect the rest (Lockheed \& Harris, 2005). Every day, the students learned one new letter and practiced it in conjunction with previously learned letters. Initially the combinations are few and limited, but as more letters are introduced, words, phrases and sentences can be formed with previously learned letters.

Based on the research conducted by Abadzi $(2012,2013)$ after 100 days of instruction, students should be able to identify letter sounds in Chichewa and use their knowledge of letter sounds to decode words. To speed up reading and prevent forgetting, literacy instruction was negotiated for four or five hours per week as discussed above. Reviews were included every four letters (see details below). These decoding skills are also expected to translate later into English reading, when the identification of letters and the sounds they make can be added onto with the additional phonetic rules in English.

Textbook development. Practicing reading to attain automaticity requires sizeable amounts of text, but the existing textbooks focus on whole words and pictures, and contains little text for reading practice. For this reason, the MVP Education team prioritized the development of a supplementary reading textbook. The MVP Education Sector in conjunction with the government's Primary Education Advisor (PEA) in the district has developed a supplemental textbook for students, teaching them the Chichewa alphabet introducing one letter at a time (focusing only on lower case letters to begin with, and later adding a second book to introduce capital letters). Each chapter includes blended sounds, short words, and basic sentences. MVP staff and the PEA sat together to generate appropriate nonsensical and real words based on the letters being introduced. All team members, to spark ideas of appropriate vocabulary for children of this age, also referred to other textbooks and classroom resources during this process.

The supplemental textbook "Bukhu Lothandizira Kuwerenga " consists of 30 'chapters', one for each of the 24 letters in the Chichewa alphabet and a review after every four letters taught. ${ }^{8}$ Each "letter chapter" consists of 4 pages, the first introduces the letter in large varying font sizes and a picture of a keyword that mimics the sound the letter makes. Analogies are letter blends of a consonant and a vowel also known as syllables. Chichewa sounds are most commonly taught through syllables, with a consonant preceding a vowel. However, in Bukhu Lothandizira Kuwerenga, all possible analogies that did not break the rules of the language were included.

In the earlier chapters, non-real words are included for students to practice sounding out the letters they have learned so far and increase speed in their identification. The teacher is to explain to the student that these are not real words with meaning, but that they are meant for practice, so that children do not hesitate to read them aloud. Once enough letters have been introduced, reading practice is focused more on real words, and eventually short sentences on pages 3 and 4 of each chapter.

After four letters are taught, we included a review chapter, for students to review the previous 4 letters they learned. This chapter does not introduce anything new, but rather reiterates the letter sounds, blends, nonsense and real words introduced previously. The book also includes a page of writing practice, for students to become familiar with the visualization and writing of the letters they have learned. The capitals chapters presumed that all lowercase letters had previously been taught and mastered by the students. It introduced capital letters in the same letter frequency order as was introduced in the first supplemental textbook. The chapters of the capitals book were shorter, only two pages per letter, and included more text for reading practice. Teachers were instructed to begin teaching the capital letters once all the lower case letters had been introduced.

\section{Methods: Study Design and Implementation}

\subsection{Description of Intervention}

The project intervention has been rolled out to 27 of the VLCs, with the exception of two, that were randomly selected to have as comparison. Time and funding limitations made it impossible to offer oral reading tests to every child. For this reason, using a random draw of lottery, from the 5 selected VLCs, 2 VLCs were kept as controls, 3 were exposed to a new methodology of learning. The results of this pilot study would help to further scale-up this approach to the rest of

\footnotetext{
${ }^{8}$ Note there is no letter $\mathrm{Q}$ or $\mathrm{X}$ in the Chichewa alphabet
} 
the VLCs who didn't receive the "treatment". It is important to note here that this cognitive neuroscience based method of acquiring literacy has already been proven in places in Gambia and elsewhere. Therefore, the objective of this pilot intervention was not to evaluate the impact of this method, but to contextualize the method in the Malawi setting. Therefore, taking a small sample would help to contextualize and fine-tune the "learning package" in greater detail. This pilot study focused on developing the learning package that is already proven elsewhere to be contextualized to the Malawi setting and used for a larger sample of VLCs later. While doing so, data on student learning levels from the control and treatment group was also collected. Baseline data was collected from a sample of 112 students from five of the VLCs (three that received the intervention, and 2 did not). Ninety of these students were tracked again for an end line survey to measure progress.

First, each student was provided with his or her own copy of the supplemental textbook created for this pilot. Second, intervention CEWs attended 4 trainings over the course of 6 months to introduce them to the material and new methodology, teach them the letter sounds of the alphabet, introduce best practices, and provide general feedback based on classroom observations done by the MVP team and to share preliminary results.

In addition, VLCs receiving the intervention package were more closely monitored and supervised than comparison classes, to ensure that the methodology was being implemented and to take lessons learned to be shared with the wider group. Due to distances and time constraints, VLCs were only observed twice at most, but previously they had not received any supervision at all so any classroom observations and direct feedback proved useful to the CEWs. VLC classes in Mwandama MVP are typically held weekly, for two-hour sessions but for the purposes of this intervention, additional instructional time was added. During the course of this pilot project, all CEWs (intervention and comparison) held classes four hours per week, spread out over 2-4 days depending on availability of community space and CEW schedule. All CEWs were provided with an additional 7500 Malawi Kwacha (approximately \$19 USD, which is half of their regular monthly salary) monthly to accommodate for this adjustment. In five VLCs, more than one CEW teaches class there at a time, and typically children are grouped according to grade level during these sessions. However, during this intervention CEWs were encouraged to group children according to reading levels, and not their grade levels.

\subsection{Teacher Training}

An initial training for CEWs receiving the intervention was conducted in early July 2014. MVP staff, in conjunction with the Primary Education Advisor, led this training to introduce this project to the CEWs to: explain its purpose and emphasis on local language literacy, plan for the intervention, and give specific teaching techniques and instructions. During this initial full-day training, CEWs were taught how to use the supplementary textbook, create teaching and learning materials to reinforce letter recognition, letter sounds, and decoding skills. In particular, significant time was spent reviewing individual letter sounds, which are not typically taught in Malawian schools that teach early primary students to decode through the recognition of common syllables that are combined to make up words.

Emphasis was also placed on classroom management techniques, such as peer-to-peer learning i.e. using older students to help guide younger struggling students, and certain pedagogical practices, such as providing individual feedback to each student and stressing the 'I do, we do, you do' approach. Individual reading practice was stressed and it was suggested to each CEW that a portion of the class be set aside ${ }^{9}$ for individual reading practice. During individual reading practice, students were encouraged to point to the letters, words, and sentences as they sounded them out in order to reinforce letter recognition with sounds.

Portions of the supplementary textbooks were distributed at the end of each of the CEW trainings, with each CEW receiving enough for every child to receive his/her own textbook. Due to fluctuations in VLC attendance over the course of the program, some students were asked to share their textbook with another student. However, it was rare for more than 2 students to be seen sharing a textbook and the vast majority of observed students each had their own book during VLC lessons. Students were not permitted to take the books home and CEWs were responsible for their maintenance. Each CEW was given a copy of the supplemental textbook for their own reference and encouraged to make instructional notes in their copies during trainings.

Many of the skills and teaching techniques introduced during the first training asked CEWs to abandon the teaching norms and traditions they've been accustomed to through their own experiences in school, often defined by practices such as rote memorization and repeating without really reading. Additionally, the specialized curriculum implemented during the MVP literacy program marked a distinct departure from the content previously taught by CEWs in their VLCs, which mainly included homework help. The transition for both CEWs and students to the new VLC content and approach took time, and observations showed months into the program, that CEWs and students often struggled to adjust to the new resources, pedagogy, and content.

\footnotetext{
920 minutes was later suggested to CEWs as ideal time for individual student reading practice. This amount of time was suggested empirically, given class duration.
} 
In the weeks following the initial July training, MVP staff conducted classroom observations of VLC classes, and provided CEWs with immediate feedback so improvements could be made continuously throughout the duration of the program. Lessons learned from these observations were used to create content for a half-day ${ }^{10}$ refresher training held in late July. In mid-August, an additional half-day refresher training was held to share preliminary baseline results from the selected intervention and comparison VLCs and instructional videos were shown from the Gambia pilot that informed many of the practices adapted for the MVP literacy program. The videos highlighted Gambian teachers conducting lessons that represented good classroom management techniques and proper use of supplementary reading resources. Also portrayed were teachers providing students with individual feedback and managing individual student reading practice. VLC classroom observations done shortly after this training revealed CEWs successfully mimicking many of the best practices exemplified by the Gambian teachers.

An additional half-day training was provided by the MVP Education staff and PEA in November to share midline results with the CEWs, discuss their reactions to the results, address recurrent program challenges \& content areas that needed strengthening, as well as to introduce new capital letter content $\&$ resources. The new capital letters content was introduced to all CEWs by the PEA, followed by the distribution of capital letter books developed by the MVP Education Team and partners to build upon the initial Bukhu Lothandizira Kuwerenga resource. A review of lesson planning and literacy activities to pursue in the VLCs was also incorporated into the training.

\subsection{Data Sources: Assessment Test}

Baseline data was collected from a sample of 112 students from five of the VLCs and 90 of these students were tracked again for an end line survey to measure progress. An adapted version of the Early Grade Reading Assessment (EGRA) in Chichewa, implemented nationally by RTI, USAID and the Ministry of Education was used as the tool to measure student reading ability. Four of the EGRA subtests were used in order to maintain simplicity and measure key indicators relevant to the content of the literacy program. The subtests measured student knowledge of letter names, letter sounds, familiar words, and oral reading fluency and reading comprehension, in a series of timed tests. Knowledge of letter sounds, reading fluency, and comprehension skills were measured from baseline to end line. MVP used the 2013 version of the EGRA test students at baseline and midline, and the latest version from September 2014 for end line surveys, provided to us by RTI Malawi country office, jointly developed with the MoEST. Table 1 presents the baseline and the endline results for both the intervention and comparison group.

Table 1. Number of Students Assessed by Grade, Treatment Status: Baseline and Endline

\begin{tabular}{|c|c|c|c|c|c|c|c|c|}
\hline & & & & Gr & & & & \\
\hline & 1 & 2 & 3 & 4 & 5 & 6 & $7^{11}$ & Total \\
\hline Intervent & & & & & & & & \\
\hline Baseline & 23 & 13 & 10 & 15 & 9 & 2 & 1 & 73 \\
\hline Endline & 20 & 12 & 9 & 11 & 8 & 2 & 1 & 63 \\
\hline Compari & & & & & & & & \\
\hline Baseline & 7 & 10 & 4 & 13 & 4 & 1 & 0 & 39 \\
\hline Endline & 3 & 7 & 3 & 10 & 3 & 1 & 0 & 27 \\
\hline
\end{tabular}

\section{Results and Discussion}

The key indicators for this pilot study are fluency and accuracy, with respect to letter sounds and words. The goal was to assess how many and what percentage of letter sounds a student can correctly identify after completing this program, focused on teaching letters. Additionally, for students who had grasped the knowledge of letter sounds, we sought to measure their ability to read words, correctly and fluently. For this study, the fluency measures are calculated as words read correctly per minute and letter sounds correctly identified per minute. The accuracy measures are noted as percentages correct.

Typically early grade readers should be reading 60 words per minute in English, in order to have enough of the content in working memory to be able to comprehend the text (Piper, 2010). Chichewa is a Bantu language that includes many agglutinative words, meaning that a single word can actually include various prefixes and suffixes making it into a more complex word or even a sentence within one word (Piper, 2010). Comparing oral reading fluency scores by tallying the words read per minute can disguise the differences between languages, especially since some Chichewa words are significantly longer than English words. While, word correspondence between Chichewa and English has not been calculated, Swahili, which is in the same family of Bantu languages as Chichewa, has a 1.3 factor corresponding to

\footnotetext{
${ }^{10}$ Half-day typically refers to 4 hours of training

11 Because the sample size of Standard 5, 6, 7 students was so small, the charts and graphs in the data analysis section combined the results for these 3 grades into one category, labeled as Standard 5.
} 
English (Piper, 2010). That is, if the reading fluency threshold for comprehension is 60 words per minute in English, than the equivalent in Swahili would be 46 words per minute. For the purposes of this study, the same threshold is used for Chichewa.

The Ministry of Education in Malawi has lower benchmarks for fluency. For Standard 2 students, the MoEST benchmark for fluency is 20 correct words per minute and 50 correct words per minute for Standard 4 students (USAID, 2013). The EGRA coordinating committee in Malawi used a slightly different set of standards, at 20 correct words per minute for Standard 1 students and 45 correct words per minute for standard 3 students (USAID, 2013). For the purposes of this study, both the benchmarks from neurological research (Piper, 2010) and the MoEST in Malawi (USAID, 2013) are indicated on the graphs. MVP considers the 46 words per minute benchmark to be the basic threshold for understanding text.

The most improvement between the intervention and comparison groups was in the 'letter sounds' category, in which students in the intervention group knew almost 13 more letter sounds per minute than their counterparts. Intervention group students also were more accurate in their knowledge of letter sounds, with an average of $62 \%$ correct by endline. Much of the content of the literacy program surrounded teaching letter sounds, and blending them together to make syllables and words. Due to the emphasis on letter sounds during both teaching and training, the improvement in letter sounds for intervention groups indicates successful implementation of the program.

Students in the intervention group also read words more accurately than those in the comparison group. While the difference between the number of words read per minute (fluency) between the two groups was small (1.2 words per $\mathrm{min}$ ), the intervention group read words with $56 \%$ accuracy by endline. The literacy program was designed to help students improve their reading fluency, but observations suggested that the majority of instructional time was focused on letter sounds and that many children had not yet progressed to reading whole words. Additional time for reading practice would be needed, and students of varying levels would need to be taught separately to cater to their different reading abilities. The increase in performance for the intervention group in the letter sounds and words test indicate that the program did have an effect on the students, but that more work is needed to have a greater impact in the area of fluency.

It should be noted that neither group improved in the reading comprehension test; in fact, both groups' scores declined. However, the intervention group attempted more questions than the comparison group, indicating that they were able to read more of the story. Since both groups had a fluency rate below 46 words per minute, which research suggests is the minimum threshold for understanding text, the students did not perform as expected on the comprehension section. ${ }^{12}$ This may be because of the test itself was more difficult, or due to the fact that students did not have the minimum threshold for reading fluency to allow for understanding.

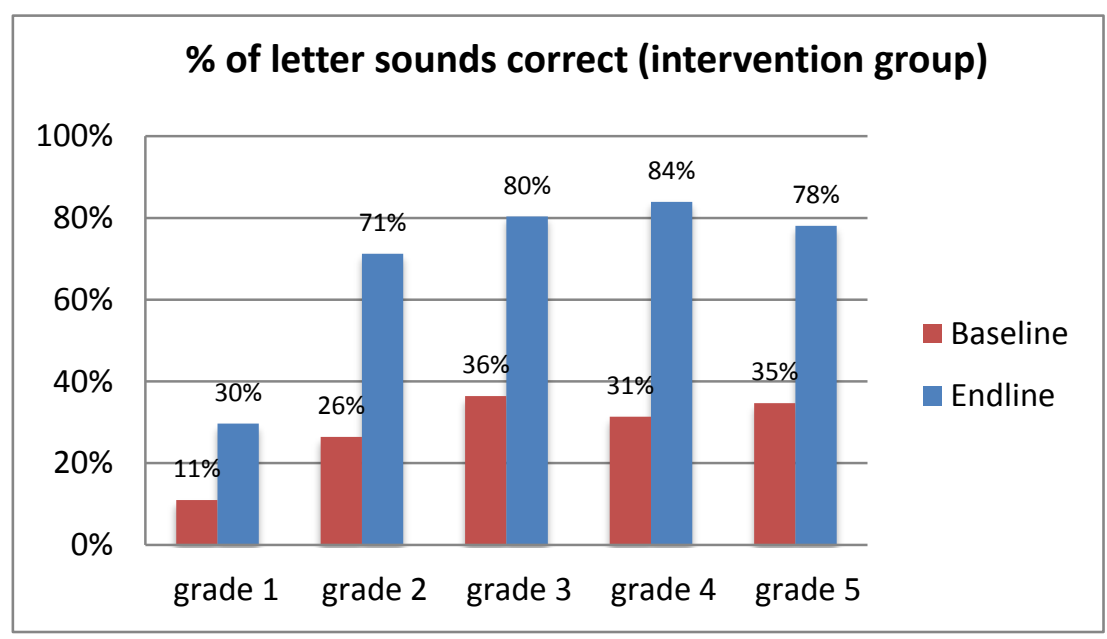

Figure 1. The improvement from letter sounds known at baseline to end line for the intervention group

\footnotetext{
12 The threshold for words per minute for students to understand text is 60 WPM in English, which equals about 46 WPM in Chichewa (using the same approximation as Swahili for ratio of agglutinative words to English words). Research Triangle Institute (2010).
} 


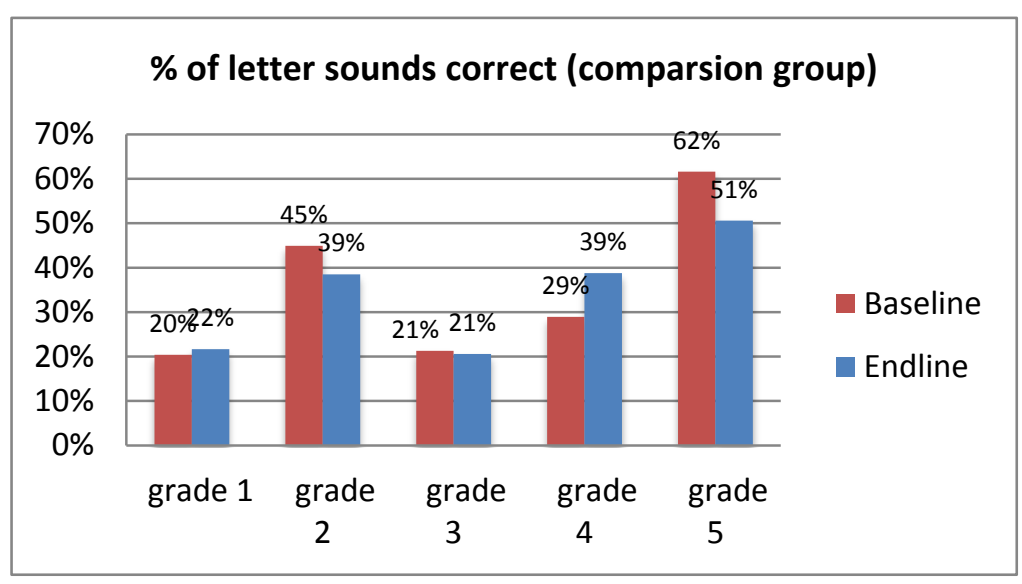

Figure 2. The improvement in letter sounds known at baseline to end line for the comparison group

Figure 1 and 2 presents the improvement in letter sounds known at baseline to end line for the comparison group. Comparisons by grade between the groups indicate some interesting variances. With respect to letter sounds, all intervention groups improved by the end of the program, with a $45 \%$ increase for grade 2, $44 \%$ for grade 3,53\% for grade 4 , and $43 \%$ for grade 5 . Grade 1 students improved as well, but only by $19 \%$. Given that this program was aimed to improve letter sound knowledge and reading fluency for the earliest readers, these modest improvements by grade 1 students indicate that the program needs to put more emphasis on the improvement of the early grade reading skills. The number of correct letter sounds per minute follows the same pattern as the percentage of letter sounds correct (above), with the majority of improvement in grade 4, followed by grade 3,5 and 2 respectively. While grade 1 students did improve, their improvement was minimal, indicating that the earliest readers did not learn as many letter sounds as the rest of the class. Thus, it is clear that the program is failing to provide improvements for the youngest age group.

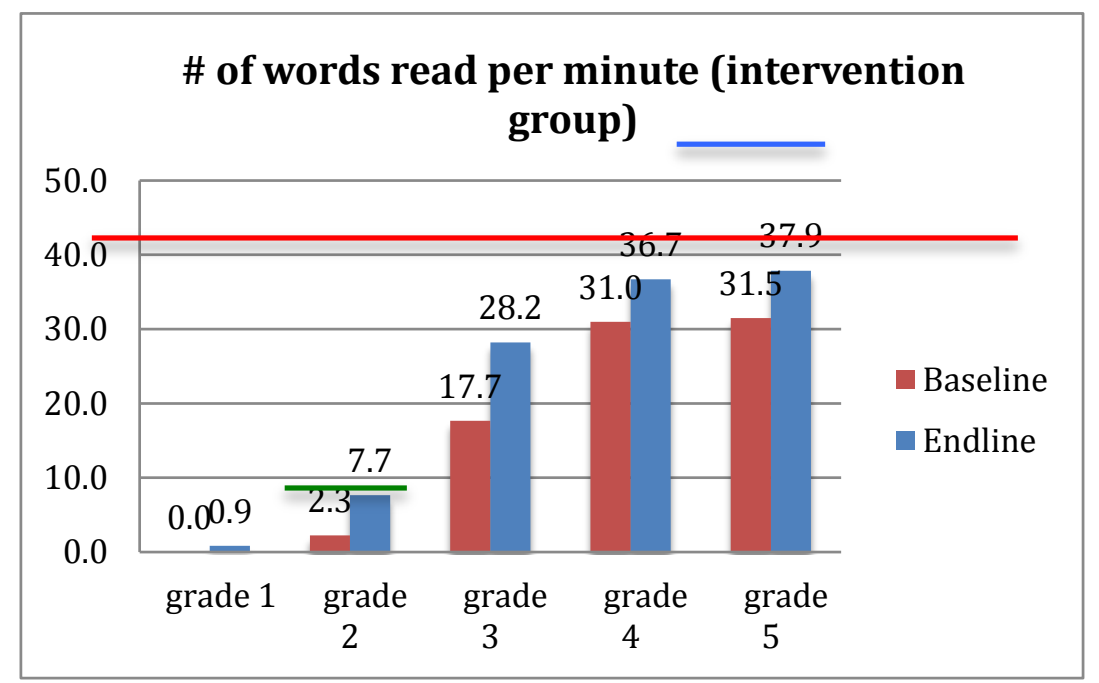

Figure 3. Words read per minute (based off the familiar word reading subtest) for intervention group 


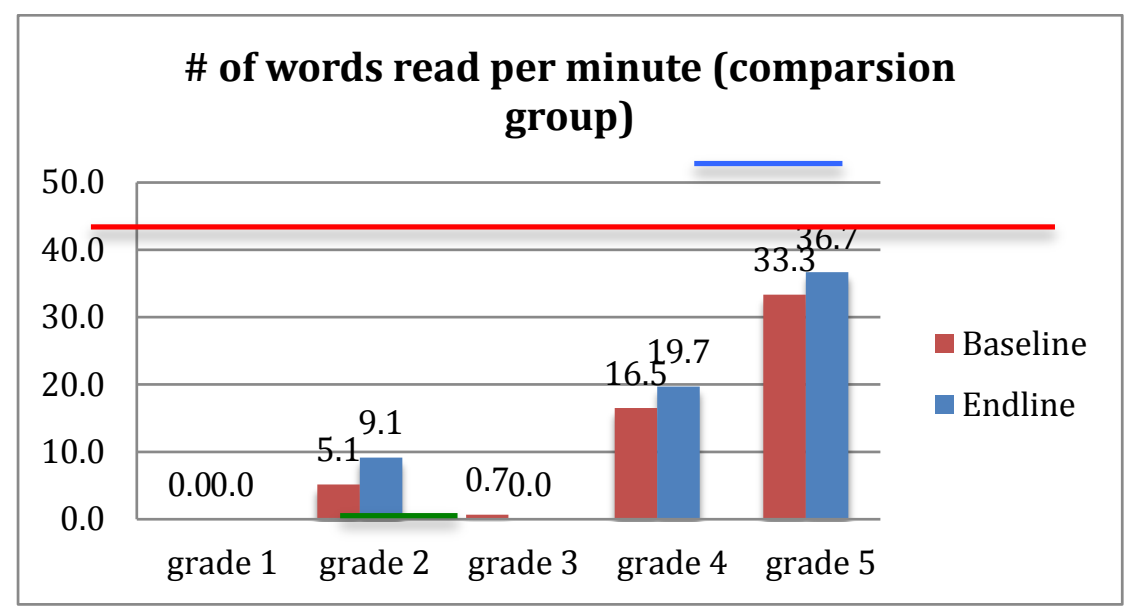

Figure 4. Words per minute (based off the familiar word reading subtest) for comparison group

MoEST benchmark Std 2 (USAID, 2013): $20 \mathrm{wpm}$

MoEST Benchmark Std. 4 (USAID, 2013): 50 wpm

Piper, (2010): $46 \mathrm{wpm}$

*note $60 \mathrm{wpm}$ is the base fluency rate for English. Chichewa is a Bantu language, in which the words are approximately 1.3 times as long as English words (using the same approximation as used for Kiswahili in Kenya).

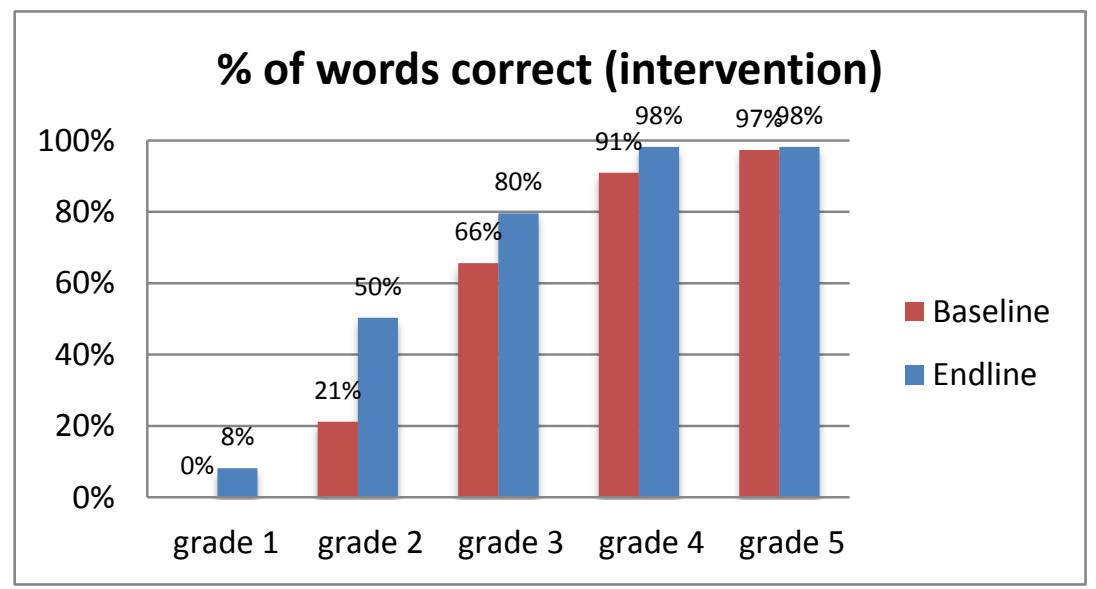

Figure 5. Accuracy on the familiar words subtest for the intervention group

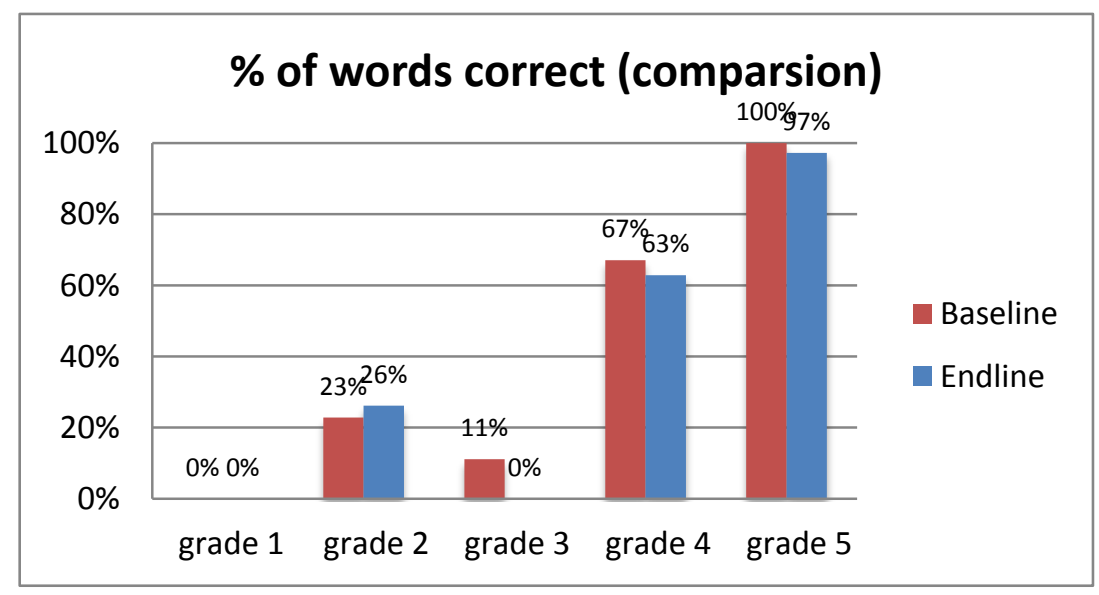

Figure 6. Accuracy on the familiar words subtest for the comparison group

The number of words read per minute read is given in Figures 3 and 4. The intervention group improved throughout the program with respect to the percentage of words they were able to read correctly, within a minute. Please refer to Figures 5 and 6 . The intervention group's reading accuracy improved from baseline to endline, with the majority of the 
improvement for the grade $2(29 \%)$ and grade $3(14 \%)$ students. Grade 1 students had an $8 \%$ improvement. Grade 4 and 5 students had less improvement, because their baseline accuracy scores were already above $90 \%$. Therefore, it can be implied that the more advanced readers (grade 4 and grade 5) were already reading fairly accurately, even if their fluency rate (discussed below) wasn't as high as it should be, and thus there was less room for improvement in accuracy. Grade 2 students improved the most, becoming more accurate in the words they did read, even though they too were far below the threshold of 46 words per minute. Grade 1 students improved, but not by as much as should have been expected by this program, whose content was geared towards earlier readers.

The minor gains in number of words per minute do show that the intervention group increased their fluency by more than the comparison group, but there is still more room for improvement. Grade 3 students in the intervention group showed the most improvement from baseline to end line, with small gains by grade 2, 3 and 5 students. As is evidenced by the rest of the data, grade 1 students did not improve much, suggesting that this program needs to focus more on catering towards the learning speed and levels of early readers. In addition, classroom observations as well as the data suggest that the program disproportionately favored emphasizing letter sounds, with less time given for practicing decoding and analogies, which are more complex and difficult to teach in such a large group of students. Thus, reading fluency rates only improved slightly.

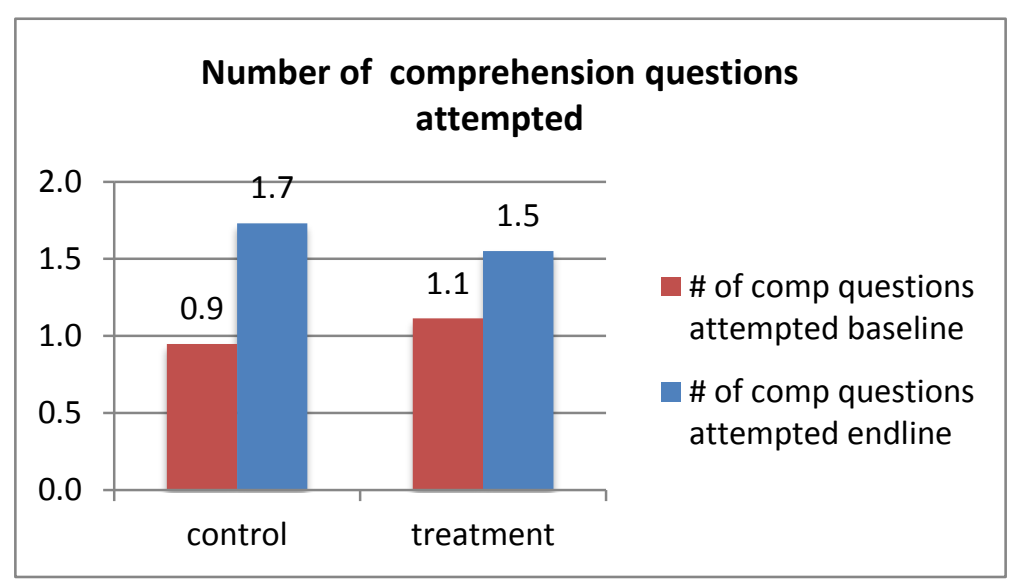

Figure 7. The number of questions a student attempted is indicative of how much of the passage they read. Based on the number of sentences they read, students were asked up to 5 comprehension questions accordingly.

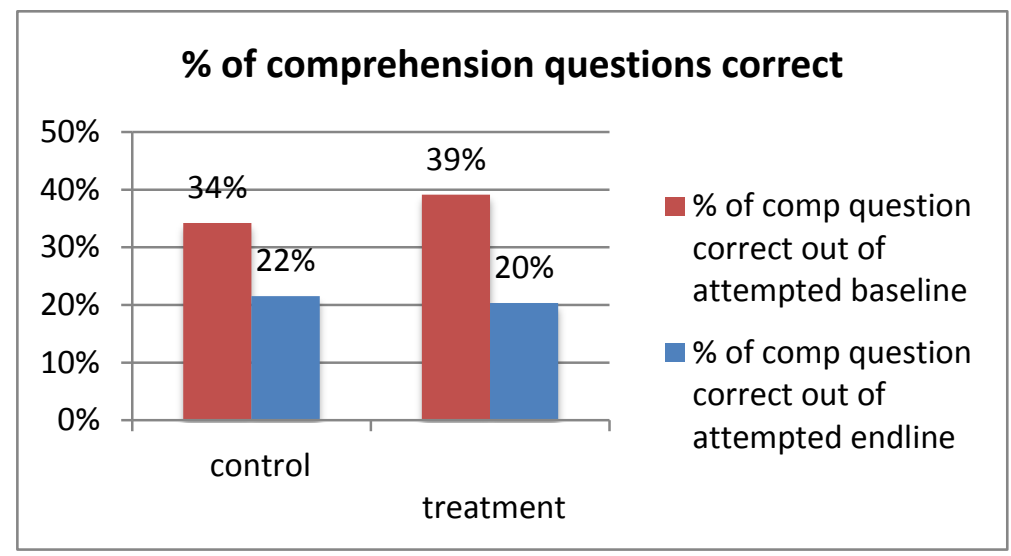

Figure 8. This graph shows the percentage of comprehension questions answered correctly out of those attempted

Figures 7 and 8 present some statistics on compression. Students' comprehension between baseline and end line for both the intervention group and comparison group declined, indicating that their reading fluency levels were not yet high enough for comprehension. In addition, because both groups declined, it is also possible that the version of the comprehension test given at end line was more difficult than at baseline, even though both versions given were the latest EGRA tests provided by RTI/USAID in Malawi ${ }^{13}$. Interestingly, both groups increased in the number of questions they attempted to answer, insinuating that they read more of the story at end line than at baseline. However the decline in

${ }^{13}$ No information on test equating was available at the time. 
performance on the comprehension questions could mean that the comprehension questions were harder or that the story was more complex to understand than at baseline. The stories given at both end line and baseline were the same length, but the baseline story had 5 possible comprehension questions and the end line story had only 4 .

\section{Classroom Observations and Study Significance}

During classroom observations and regular check-ins, the research team provided critical feedback on the following. The team emphasized that children should be given more time to practice from the beginning of this program. While this point was emphasized during trainings and classroom observations, it was not fully put into practice, therefore re-enforcement was necessary. Both students and CEWs alike were not used to spending the majority of class time on individual practice, in which students each sat with their own book and read aloud, with minimal assistance and without repeating after an older buddy or teacher. Taking into account the system that students and teachers are used to, more time must be spent during trainings and observational classroom visits demonstrating how to encourage students to practice reading individually, how to manage large classes, and how to keep their attention focused. As most schools conduct lessons in a teacher centered fashion, with most reading done in a read and repeat fashion, breaking these habits and changing class dynamics to focus on individual reading practice requires more emphasis and specified training techniques.

Most CEWs surveyed about their experience in this program all requested more training days, and more frequent trainings. With this pilot, video clips of best practices were incorporated into trainings halfway through the program, after which some habits were already set. Going forward, a collection of best practice videos for teachers should be used to model teaching techniques, classroom management, and successful strategies from the earliest onset of the program. Closer supervision and real time feedback, along with more training would also have benefitted the CEWs and caught some of the challenges and mistakes earlier on. Supervision and feedback support needs to continue through the end of the program.

One of the challenges with this pilot was the composition of VLC classes, which were not always held in environments conducive to learning. Some VLCs had desks and chairs, some had an enclosed space free from distractions where students sat, and others were just held in outdoor spaces in the middle of villages in which there was no structure for classes to be held. The VLCs are optional after school activity for students to attend. While CEWs do encourage all children to participate and attend, absenteeism is common since parents need domestic support and there are other after school activities organized by schools or other NGOs which students may be attending. In addition, because many VLCs are held in community-donated spaces, other community events such as funerals and functions would disrupt CEWs ability to hold classes. Mambo and Hendere VLC were held outside people's homes, and thus on days with poor weather forming groups, using books, and even holding class could be difficult.

VLC classes also combined students from pre-school until grade 6, which made classroom management very challenging. The basic content of this program was aimed towards early readers, primarily grade 1-2. Because classes contained older readers, it became difficult for CEWs to focus their efforts on the younger students. Separate content for reading practice should be included for older students, to improve their fluency without them getting bored by the more simple materials for earlier grades.

Part of the implementation took place during July and September, which are months when initiation ceremonies take place in parts of the project area. All children, who have not already been initiated, are expected to go, requiring them to be absent for an entire month in the "bush." The target age of initiates range from 6 years old and up. This practice greatly affected VLC attendance and many of the assessed learners who were initiated missed consecutive weeks of the program intervention. During this period there are also parties that are organized for the initiates, which also may have contributed to low attendance rates during initiation periods.

The timeline of this pilot also presented a slight challenge with enrollment fluctuations, as new students joined the classes at the beginning of the school year in September. Thus, they were already behind in the material at that point. Also, some children were attending VLC with older siblings or were younger than school going age but coming over the summer months to prepare for entering Standard 1. Therefore they may have not have had ever been to school before.

The CEWs need more practice with the letter sounds, reemphasizing the correct pronunciations and not focusing on letter sounds. CEWs could make an audio recording of the correct letter sounds on their phones so that they can continue to practice. Any CEW should be able to correctly say all the letter sounds in the alphabet when asked, during training, observation, or by a student. All program advisors and classroom supervisors must themselves be on the same page about the letter sounds and pronunciations, prior to training the CEWs and consistency should be maintained throughout the program.

The wide array of analogies, syllables and diphthongs introduced in each chapter were arbitrarily chosen. It became 
increasingly apparent throughout classroom observations that some letter combinations, analogies, and diphthongs were presented in a way that was not common in Chichewa. After this pilot, feedback from teachers, student observations, and language experts were included to update the way in which analogies and diphthongs are presented. In some instances, there were too many different analogies per chapter, and perhaps a few should have been repeated more often. A revised version of the supplemental textbook was created after the pilot.

A lesson learned from this pilot was to set specific realistic and quantifiable goals as well as milestones from the beginning. It would have been best to share data with CEWs from the baseline during the first training, showing them where their students were and discussing which content areas of this program could improve which data points. As an organization, MVP could have engaged the CEWs in setting goals for their students, and then checking in on progress towards these goals throughout the course of the program. The team could have shared with them the EGRA test format, teaching them what it measures, and ask them at different stages throughout the program if they thought their students could identify letter sounds, read at the expected fluency level, and comprehend text. Knowing the structure of the test might also have helped CEWs understand the data better.

It would also have been useful to give CEWs formative and summative assessments they themselves could have used during class to measure student progress. The only form of measurement of this program was the EGRA tests conducted with the intervention and comparison groups, and thus VLCs and students not selected in the sample had no formal measurement of student achievement and progress. Many students reported feeling left out of the process because they were not selected in the sample of students for the EGRA tests. Thus, alternative quick assessments that CEWs could engage students in would have been incredibly helpful.

Ideally, this program would have involved policy makers and other education partners more closely from the beginning, particularly during the development and design of the lesson content and book structure. Involving policy makers and linguistic experts in country would have helped gain more traction to be able to advocate for support from a policy level for such a program. As other partners were also involved in literacy programs within Malawi and the Zomba region, doing a more comprehensive analysis of their content, structure, and collaborating a more cohesive approach may have been helpful. While RTI, Save the Children, and MVP are all focusing on literacy and taking many of the same strategies and approaches, their programs all differ in some ways. A more collaborative approach amongst all stakeholders would have helped streamline support for schools and students, shared important lessons learned and materials, and been less confusing for policy makers when approached for expansion of each organizations methodology.

It is important to keep in mind that the purpose of this study was to implement an already tried and tested model where the same cognitive neuroscience principles were applied. Therefore, the study focused on the teacher training, development of textbook and classroom based instruction more than conducting an evaluation of already proved methodology. Some of the lessons learned from this pilot will inform targeted policy recommendations and tactics for scaling up this initiative. A next key step will be to fine-tune the supplementary textbook, updating its content and format based on classroom observations, teacher feedback, student interactions, and end line test results. Words and sentences can be added or removed, font size changed, and formatting can be upgraded based on the field pilot. There is also a need to see how to best introduce capital letters, in a more structured manner. In addition, results from this study can inform plans to advocate for this program to be expanded to early grades in government schools. Additional time must also be spent seeing how this supplementary textbook can accompany and complement school textbooks. Content for teacher training and lesson structure will be informed by the ongoing classroom observations and test results we receive. Based on these initial revisions and recommendations, due to the low cost and promising initial results, the project could be scaled-up in formal schools in Malawi and elsewhere where the emphasis is on local language learning.

\section{Acknowledgement}

The authors would like to thank the staff of the Millennium Villages Project in Mwandama Malawi to make this study possible. Special thanks to Dr. Andrew Daudi for his leadership to oversee the Education Sector activities. The authors would also like to thank Petros Musukwa who tirelessly helped with the training, classroom observations and data collection for this project. Thanks to Vivian Liu for helping with data analysis.

\section{References}

Abadzi, H. (2012). Effective teacher training in low-income countries: the power of observational learning research (English). Accessed from http://documents.worldbank.org/curated/en/docsearch/author/m93113

Abadzi, H. (2013). Raising literacy from 20 percent to 80 percent? : A science-based strategy for GPE partner countries (English) Accessed from http://documents.worldbank.org/curated/en/docsearch/author/m93113.

Arai, J., Li, S., Hartley, D. M., \& Feig, L. A. (2009). Transgenerational Rescue of a Genetic Defect in Long-Term 
Potentiation and Memory Formation by Juvenile Enrichment. The Journal of Neuroscience, 29(5), 1496-1502. http://dx.doi.org/10.1523/JNEUROSCI.5057-08.2009

Beatty, A., \& Pritchett, L. (2012) From Schooling Goals to Learning Goals: How Fast Can Student Learning Improve? http://www.cgdev.org/files/1426531_file_Beatty_Pritchett_Time_to_MLG_FINAL.pdf: Center for Global Development.

Center for Universal Education at Brookings. (2011). A global compact on learning. Taking action on education in developing countries.

http://www.brookings.edu/ /media/research/files/reports/2011/6/09\%20global\%20compact/0609_global_compact. pdf: Center for Universal Education at Brookings

Chilora, H. (2000). Language Policy, Research and Practice in Malawi. Paper presented at the Comparative and International Education Society (CIES) 2000 Conference in San Antonio, Texas. http://pdf.usaid.gov/pdf_docs/pnack274.pdf

DeJongh, M. (2014). Best practices for developing supplementary reading materials. Executive Summary. USAID.

Feldon, D. F. (2007). Cognitive load and classroom teaching: The double-edged sword of automaticity. Educational Psychologist, 42(3), 123-137. http://dx.doi.org/10.1080/00461520701416173

Franceschini, S., Gori, S., Ruffino, M., Pedrolli, K., \& Facoetti., A. (2012). A Causal Link between Visual Spatial Attention and Reading Acquisition. Current Biology, (2012). http://dx.doi.org/10.1016/j.cub.2012.03.013

Lockheed, M., \& Harris, A. (2005). Beneath Education Production Functions: The Case of Primary Education in Jamaica. Peabody Journal of Education, 80(1), 6-28. http://dx.doi.org/10.1207/S15327930pje8001_2

Marinelli, M., Martelli, M., \& Zocolotti, P. (2012). Visual and linguistic factors in literacy acquisition: Instructional Implications for Beginning Readers in Low-Income Countries. Washington, DC: World Bank, GPE Working Paper Series on Learning, no . 2 .

Moyo, T. (2001). The Changing Language Policies and Reversing Language Roles in Malawi: From Colonial Times (1891-1964) to the Present. Per Linguam, 17(2) 1-11. http://perlinguam.journals.ac.za/pub/article/view/1/9

Piper, B. (2010). Kenya Early Grade Reading Assessment Findings Report, July 2010. William and Flora Hewlett Foundation.

Research Triangle Institute. (2010). Kenya Early Grade Reading Assessment Findings Report, July 2010. William and Flora Hewlett Foundation.

Seymour, P. H. K., Aro, M., \& Erskine, J. M. (2003). Foundation literacy acquisition in European orthographies. British Journal of Psychology, 94, 143-174. http://dx.doi.org/10.1348/000712603321661859

US Embassy, Lilongwe, Malawi (2015, January 15). http://lilongwe.usembassy.gov/advising_services6.html Retrieved January 2015.

USAID (2012). Early Grade Reading Assessment. (EGRA): Egypt Progress Report-Girls' Initiative on Learning Achievement (GILO) September 2011. Research Triangle Institute.

USAID (2013). Early Grade Reading Activity (EGRA) Impact Evaluation Baseline Report. Malawi.

UWEZO Kenya (2012). Are Our Children Reading? Summary of Key Findings. Primary Facts on Learning Levels. http://www.uwezo.net/wp-content/uploads/2012/08/Summary-Findings-A4-Primary-Facts-FOR-WEB.pdf. UWEZO, Kenya

UWEZO Tanzania (2011). Are Our Children Reading? Summary of Key Findings. Primary Facts on Learning Levels http://www.uwezo.net/wp-content/uploads/2012/08/TZ_2011_AnnualAssessment-Report.pdf UWEZO, Tanzania.

UWEZO Uganda (2011). Are Our Children Reading? Summary of Key Findings. Primary Facts on Learning Levels. http://www.uwezo.net/wp-content/uploads/2012/08/UG_2011_AnnualAssessmentReport.pdf UWEZO, Uganda

Zafeirakou, A. (2014). Going to scale with reading reform: what the Gambian government has learned from its reading experiments. Washington DC: World Bank; Global Partnership for Education Working Paper

\section{$(\mathrm{cc}) \mathrm{BY}$}

This work is licensed under a Creative Commons Attribution 3.0 License. 